\title{
PENGARUH PENCAMPURAN SEMEN TERHADAP KUAT GESER TANAH LEMPUNG LAMPOH KEUDE
}

\author{
Muhammad Zardi ${ }^{1}$, Mukhlis ${ }^{2}$ \\ ${ }^{1), 2)}$ Program Studi Teknik Sipil, Fakultas Teknik, Universitas Abulyatama \\ J1. Blang Bintang Lama Km 8,5 Lampoh Keude Aceh Besar, email: \\ mr_zardi@yahoo.com
}

\begin{abstract}
The aim of the tests was to investigate the influence of cement on clay of Lampoh Keude Village Kuta Baroe district Aceh Besar district. Results to be seen is parameters of shear angle ( $\phi$ ) and cohesion (c) of the direct shear test. Normal stress to be given to direct shear test is $0.305 \mathrm{~kg} / \mathrm{cm}^{2}, 0.634 \mathrm{~kg} \mathrm{~cm}$ and $1.293 \mathrm{~kg}$ $1 \mathrm{~cm}^{2}$ with optimum moisture content obtained $23.15 \%$ and the dry volume weight $1.438 \mathrm{gr} / \mathrm{cm}^{2}$. This study tested three samples for each percentage mixture of $0 \%$, $4 \%, 8 \%, 12 \%$ and $16 \%$ with one day curing period. The amount of specimen without cement mixture was made of 3 specimens and without cement mixture was made of 12 specimens for 3 repetitions testing. Soil testing in the lab include testing the physical properties of the native land, the mechanical properties of the native land and land with a cement mixture. Based on the testing of the physical properties of the native land, AASHTO classifying soil in group A-7-6 (11) and USCS classifying soil as a silt and clay in $\mathrm{CH}$ group. The addition of cement shows the stability of direct shear tests with increases of cohesion (c) and friction angle ( $\phi$ ) is $0 \%$ cement is $c=0.797 \mathrm{~kg} / \mathrm{cm}^{2}$ and $\phi=31.45^{\circ}$, 4\% cement is $c=1.326$ $\mathrm{kg} / \mathrm{cm}^{2}, \phi=36,22^{\circ}, 8 \%$ cement is $c=1.529 \mathrm{~kg} / \mathrm{cm}^{2}$ and $\phi=38,55^{\circ}, 12 \%$ cement is $c=1.950 \mathrm{~kg} / \mathrm{cm}^{2}, \phi=38,11^{\circ}$ and $16 \%$ cement is $c=2.084 \mathrm{~kg} / \mathrm{cm}^{2}, \phi=39,01^{\circ}$. Direct shear test results by mixing cement on clay showed an increase cohesion (c) and friction angle $(\phi)$ parameters.
\end{abstract}

Keywords : clay, cohesion, friction angle, direct shear.

\begin{abstract}
Abstrak: Penelitian ini bertujuan untuk mengetahui pengaruh semen terhadap tanah lempung Desa Lampoh Keude Kecamatan Kuta Baroe Kabupaten Aceh Besar. Hasil yang ingin dilihat adalah parameter sudut geser (ø) dan kohesi (c) dari pengujian geser langsung (direct shear test). Tegangan normal yang diberikan untuk pengujian geser langsung adalah $0,305 \mathrm{~kg} / \mathrm{cm} 2,0,634 \mathrm{~kg} / \mathrm{cm} 2$ dan 1,293 $\mathrm{kg} / \mathrm{cm} 2$ dengan kadar air optimum yang diperoleh $23,15 \%$ dan berat volume kering $1,438 \mathrm{gr} / \mathrm{cm} 2$. Adapun dalam penelitian ini diuji tiga sampel untuk masing-masing persentase campuran $0 \%, 4 \%, 8 \%, 12 \%$ dan $16 \%$ dengan masa pemeraman 1 hari. Benda uji tanpa campuran semen dibuat 3 buah dan dengan campuran semen dibuat 12 buah untuk 3 kali pengulangan pengujian. Pengujian tanah di laboratorium meliputi pengujian sifat fisis tanah asli, sifat mekanik tanah asli dan tanah dengan campuran semen. Berdasarkan pemeriksaan sifat fisis tanah asli, AASHTO mengklasifikasikan tanah dasar sebagai tanah berlempung dalam kelompok A-7-6 (11) dan USCS mengklasifikasikan tanah dasar sebagai tanah lanau dan lempung dalam kelompok $\mathrm{CH}$. Penambahan pencampuran semen memperlihatkan kestabilan tanah dari uji geser langsung dengan peningkatan kohesi (c) dan parameter sudut geser (ø) yaitu $0 \%$ semen sebesar $\mathrm{c}=0,797 \mathrm{~kg} / \mathrm{cm}^{2}$ dan $\varnothing=31,45^{\circ}, 4 \%$ semen sebesar $\mathrm{c}=1,326 \mathrm{~kg} / \mathrm{cm}^{2}$ dan $\varnothing=36,22^{\circ}, 8 \%$ semen sebesar $\mathrm{c}=1,529 \mathrm{~kg} / \mathrm{cm}^{2}$ dan $\varnothing=38,55^{\circ}, 12 \%$ semen sebesar $\mathrm{c}=1,950 \mathrm{~kg} / \mathrm{cm}^{2}$ dan $\varnothing=38,11^{\circ}, 16 \%$ semen sebesar $\mathrm{c}=2,084 \mathrm{~kg} / \mathrm{cm}^{2}$ dan $\varnothing=39,01^{\circ}$. Hasil pengujian geser langsung dengan pencampuran semen pada tanah lempung menunjukkan adanya peningkatan kohesi (c) dan parameter sudut geser (ø).
\end{abstract}

Kata kunci : tanah lempung, kohesi, sudut geser, direct shear. 
Tanah mempunyai kaitan erat dengan perencanaan suatu struktur bagian bawah kontruksi, seperti struktur jalan raya, bangunan, lapangan terbang, dan berbagai aplikasi lainya. Kestabilan struktur bangunan bawah ikut menentukan kestabilan struktur bangunan diatasnya. Untuk itu banyak hal yang menarik untuk dipelajari tentang prilaku kekuatan tanah bawah kontruksi.

Salah satu yang harus diperhatikan dalam pemilihan bahan kontruksi terhadap tanah adalah kuat gesernya. Kekuatan geser tanah (shear strength of soil) yaitu kemampuan massa tanah dalam mempertahankan struktur butirannya yang disebabkan oleh gaya luar, baik berupa gaya tekan maupun gaya tarikan.

Kekuatan geser tanah tergantung pada parameter kekuatannya yaitu sudut geser (ø) dan nilai kohesi (c). Kuat geser tanah dipengaruhui oleh beberapa faktor seperti angka pori, ukuran butiran dan kadar air.

Pada beberapa kasus sering dihadapkan pada pemakaian tanah sebagai material bahan timbunan badan jalan (tidak memenuhi persyaratan) seperti tanah lempung kadar tinggi. Tanah jenis ini selain daya dukungnya relatif rendah juga mempunyai sifat mengembang (swelling) yang cukup besar bila jenuh air, oleh karena itu perlu ada usaha untuk memperbaiki daya dukungnya bila harus dijadikan bahan kontruksi. Salah satu upaya yang bisa dilakukan yaitu dengan menambahkan bahan stabilisasi terhadap tanah asli berupa semen.

Sehubungan dengan banyak kegunaan bahan tersebut, maka banyak hal yang harus diselidiki, terutama diketahui sifat-sifatnya dan kemampuan bahan tersebut. Sifat-sifat tanah yang ditinjau ialah sifat fisis dan sifat mekanis. Data sifat fisis dipakai untuk mengelompokkan tanah dalam suatu sistem klasifikasi, sedangkan sifat mekanis antara lain untuk mengetahui sifat kepadatan dan kekuatannya.

Tujuan dari penelitian ini adalah untuk mengetahui parameter sudut geser (ø) dan nilai kohesi (c). Hasil penelitian ini diharapkan bisa diperoleh perbandingan dalam pencampuran tanah lempung dengan bahan-bahan stabilisasi yaitu semen. Tanah yang digunakan dalam penelitian ini adalah tanah lempung yang berasal dari Desa Lampoh Keude Kecamatan Kuta Baro Kabupaten Aceh Besar. Tanah yang terdapat ditempat ini sebagian besar mengandung lempung.

\section{KAJIAN PUSTAKA}

\section{Klasifikasi Tanah}

Umumnya, penentuan sifat-sifat tanah banyak dijumpai dalam masalah teknis yang berhubungan dengan tanah. Hasil dari penyelidikan sifat-sifat ini kemudian dapat digunakan untuk mengevaluasi masalahmasalah tertentu seperti, penetuan penurunan bangunan, penetuan kecepatan air yang mengalir lewat benda uji guna untuk menghitung koefisien permeabilitas, dan untuk mengevaluasi tanah yang miring.

\section{Menurut Bowles (1993) bahwa} penentuan jenis tanah atau klasifikasi tanah 
berdasarkan pemakaian lebih memadai bagi keperluan teknik. Hal ini disebabkan karena dasar klasifikasi memperhitungkan sifat-sifat fisis tanah disamping persentase ukuran butiran. Tanah dapat diklasifikasi secara umum sebagai tanah kohesif dan tidak kohesif atau berbutir halus dan berbutir kasar. Metode yang paling umum digunakan sebagai dasar klasifikasi dalam mekanika tanah adalah sistem klasifikasi AASHTO (American association of state highway and transportation Official) dan sistem klasifikasi USCS (Unified Soil Clasification system). Kedua sistem tersebut mengelompokkan tanah berdasarkan distribusi ukuran butiran dan batas-batas Atterberg.

\section{Sistem Klasifikasi Tanah AASTHO}

Pemberiaan sebutan kelompok tanah menurut klasifikasi ini adalah berdasarkan ukuran butir butirannya.

Hal ini dikemukakan oleh Hold dan Konvacs (1981), bahwa tanah terbagi atas beberapa jenis yaitu:

- Berangkal (baulders) diameter lebih besar $75 \mathrm{~mm}$;

- Kerikil (gravel) diameter $2 \mathrm{~mm}$ sampai dengan $75 \mathrm{~mm}$;

- Pasir Kasar (coarse sand) diameter $0,425 \mathrm{~mm} \mathrm{~s} / \mathrm{d}$ diameter $2 \mathrm{~mm}$;

- Pasir halus (fine sand) diameter 0,075 $\mathrm{mm} \mathrm{s} / \mathrm{d} 0,425 \mathrm{~mm}$, dan

- Lanau lempung (silt clay) diameter butiran yang lolos saringan no.200 (diameter $0.075 \mathrm{~mm}$ ).

Tabel 1. Klasifikasi sistem AASTHO

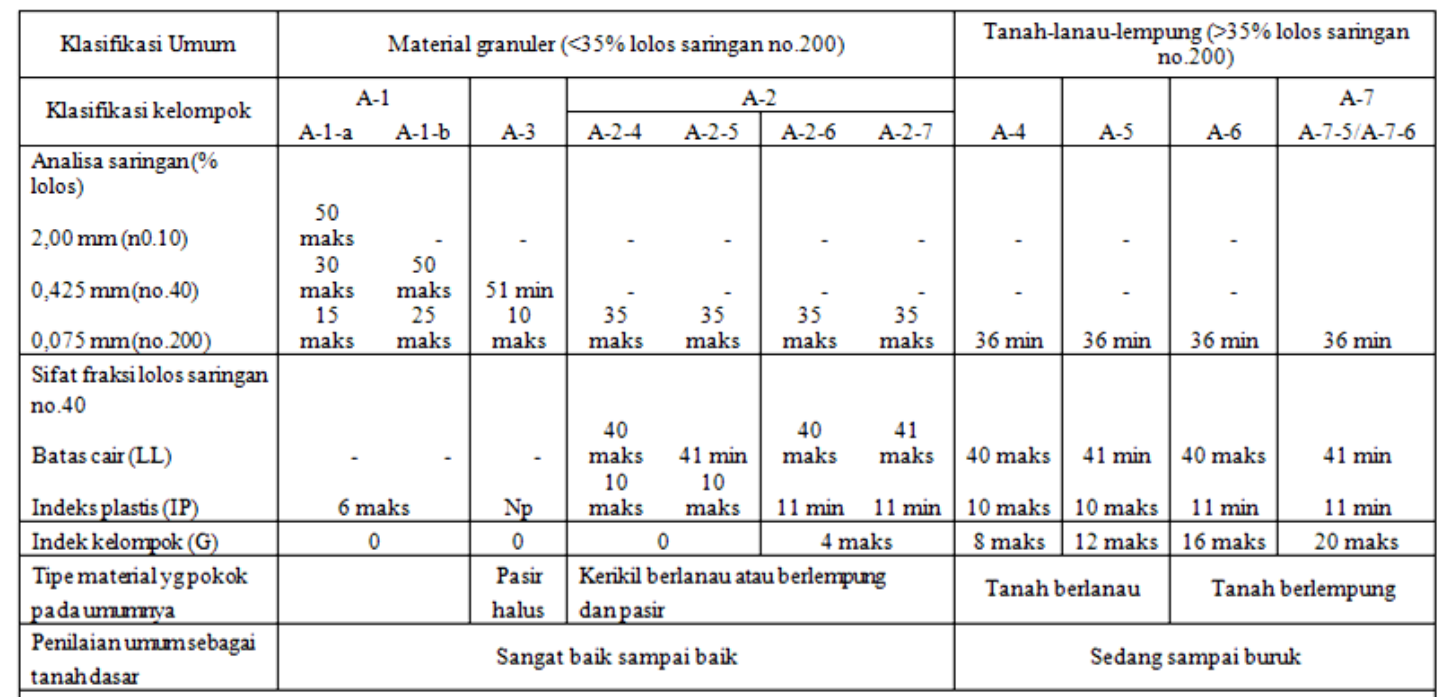

Sumber: Hary Christady Hardiatmo (2006)

Pertimbangan lain secara umum terbagi menjadi 2 kelompok yang besar, kelompok pertama adalah kelompok granular materials (bahan-bahan yang berbutir kasar), tanah yang butir halusnya (lolos saringan no. 200) paling maksimal 35\% dari berat keseluruhan massa tanah itu. Kelompok tersebut terdiri dari jenis-jenis A-1, A-2, dan A3. 
Kelompok kedua adalah yang disebut silt clay material (bahan-bahan lanau lempung) yaitu tanah yang butiran halusnya (yang lolos saringan No. 200) paling minimum 36\% dari berat keseluruhan tanah tersebut. Jenis-jenis yang termasuk kedalam kelompok ini adalah A-4, A-5, A-6, dan A-7. Ketentuan lainnya adalah banyaknya butiran yang lolos dari saringan-saringan nomor ; 10, 40, dan 200, disertai dengan tingkat batas cair, indeks plastisitas, dan indeks kelompok. Penentuan indeks kelompok tanah yang dipaparkan oleh Hold dan Kovacs (1981), dengan perumusan sebagai berikut:

$\mathrm{GI}=(0,2 . a)+(0,005 . a . c)+(0,01 . b . d)$

dimana :

$\mathrm{a}=$ bagian dari persentase yang lolos saringan No. 200 yang lebih besar dari 35 dan tidak melebihi 75, dinyatakan sebagai bilangan bulat berkisar dari 1 sampai 40)

$\mathrm{b}=$ bagian dari persentaseyang lolos saringan No.200 yang lebih besar dari 15 dan tidak melebihi 55, dinyatakan sebagai bilangan bulat (berkisar dari 1 sampai 40)

$\mathrm{c}$ = bagian dari batas cair yang lebih besar dari 40 dan tidak lebih besar dai 60 , dinyatakan sebagai bilangan bulat (berkisar dari 1 sampai 20)

$\mathrm{d}=$ bagian dari indeks palstisitas yang lebih besar dari 10 dari dan tidak melebihi 30, dinyatakan dalam bilangan bulat (berkisar dari 1 sampai 20)

\section{Sistem klasifikasi tanah USCS}

Sehgal (1979) mengemukakan, bahwa tanah yang diklasifikasikan menurut sistem ini dapat dibagi menjadi 3 kelompok utama. Pertama adalah tanah yang berbutiran kasar (Coarse Grained Soil), dengan persyaratan bahwa berat butiran yang tertinggal diatas saringan no. 200 minimum 50\%. Kedua adalah tanah yang berbutir halus (Fine grained soil), dengan persyaratan bahwa butiran tanah yang lolos saringan no. 200 minimum 50\%. Terakhir adalah berupa tanah-tanah organic (Organic soils).

Pengelompokkan jenis pertama dan kedua telah disebutkan,juga berdasarkan tingkat plastisitas dan gradasinya,tetapi kelompok yang terakhir berdasarkan pada pengamatan warna dan bau secara visual.

\section{Kuat Geser Tanah}

Parameter kuat geser tanah diperlukan untuk analisis-analisis kapasitas dukung tanah, seperti stabilitas lereng dan gaya dorong pada dinding penahan tanah. Menurut teori Mohr (1910) kondisi keruntuhan suatu bahan terjadi oleh akibat adanya kombinasi keadaan kritis dari tegangan normal dan tegangan geser.

Punmia (1980) memberikan batasan tentang kuat geser tanah yaitu kemampuan butiran tanah untuk dapat menahan (menghambat) akibat pengaruh tegangan geser yang bekerja untuk dapat menahan kondisi keruntuhannya disebut kuat geser tanah itu sendiri, sehubungan dengan hal tersebut, Takeda (1977) mengemukakan 
bahwa kuat geser tanah pada hakikatnya terdiri dari dua (2) komponen yaitu:

a. Kekuatan kohesi yang terkandung dari macam tanah dan kepadatannya, tetap tidak terganggu pada beban vertikal yang bekerja pada bidang geser.

b. Kekuatan gesekan (sudut geser dalam) yang berbanding lurus dengan beban vertikal yang bekerja pada bidang geser.

Teori tentang kekuatan geser tanah pada mulanya dikemukakan oleh Coulumb (1977) dan terakhir digenerasikan oleh Mohr (1910) berpendapat bahwa kondisi keruntuhan suatu bahan terjadi oleh akibat adanya kombinasi keadaan kritis dari tegangan normal dan tegangan geser pada bidang runtuhnya, dinyatakan dalam persamaan :

$$
\tau=f .(\sigma)
$$

Jika hubungan tegangan normal dan tegangan geser yang berupa sejumlah titik yang masing-masing dihubungkan maka berbentuk garis lengkung (kurva). Garis lengkung tersebut dinamakan selubung keruntuhan mohr (failure envelope), dengan $\tau$ adalah tegangan geser pada saat terjadinya keruntuhan atau kegagalan, dan $\sigma$ adalah tegangan normal pada saat kondisi tersebut.

Tabel 2. Klasifikasi sistem USCS

\begin{tabular}{|c|c|c|c|c|c|c|}
\hline \multicolumn{3}{|c|}{ Divisi utama } & \multirow{2}{*}{$\begin{array}{c}\begin{array}{c}\text { Simbol } \\
\text { kelompok }\end{array} \\
\mathrm{GW}\end{array}$} & \multirow{2}{*}{\begin{tabular}{|l|}
\multicolumn{1}{|c|}{ Nama jenis } \\
Kerikil gradasi baik dan campuran pasir-kerikd \\
gedikit asu tidak mengandung butiran halus
\end{tabular}} & & Nama jenis \\
\hline \multirow{8}{*}{ 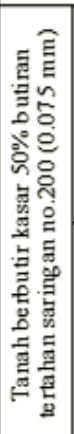 } & \multirow{4}{*}{ 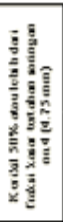 } & \multirow{2}{*}{$\begin{array}{l}\text { Kerikil bersih (sedikit } \\
\text { atan tak ada butian } \\
\text { halus) }\end{array}$} & & & \multirow{2}{*}{ 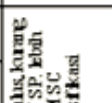 } & 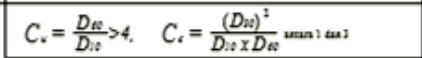 \\
\hline & & & GP & $\begin{array}{l}\text { Kerikil gradasi baik dan campuran pasi-kerikd } \\
\text { anu tidek mengandung butirn halus }\end{array}$ & & Tidak memenuhi kedua krieria unuk GW \\
\hline & & \multirow{2}{*}{$\begin{array}{l}\text { Kerikil banyak } \\
\text { kandungan butian } \\
\text { halus }\end{array}$} & $\mathrm{GM}$ & Kerikil berlanau, campuran kerikil pasi-lanau & \multirow{6}{*}{ 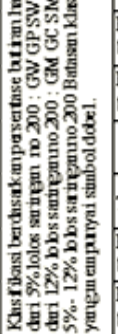 } & 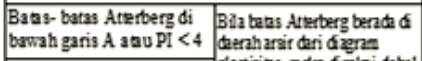 \\
\hline & & & $\mathrm{GC}$ & Kerikil berlempung, campuran kerikil pasir-lanas & & $\begin{array}{l}\text { Basas-batas Atyrberg di } \\
\text { bawah garis } \mathrm{A} \text { asu } \mathrm{PI}>7\end{array}$ \\
\hline & \multirow{4}{*}{ 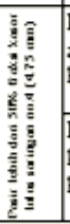 } & \multirow{2}{*}{$\begin{array}{l}\text { Kerikil bersih (sedikit } \\
\text { atas tak ada butian } \\
\text { halus) }\end{array}$} & SW & $\begin{array}{l}\text { Pasir gradasi baik, pasir betkerikit, sedkit atav idak } \\
\text { mengandung butran halus }\end{array}$ & & $C_{c}=\frac{D_{w 0}}{D_{i 0}}>\sigma, \quad C_{c}=\frac{\left(D_{D i}\right)^{2}}{D_{i 0} \times D_{w 0}}$ \\
\hline & & & SP & $\begin{array}{l}\text { Pasir gradasi buruk, pasir betkerikil, } \text { diki atav tidak } \\
\text { mengandung butran halus }\end{array}$ & & Tidak memenuhi kedua lrieria unuk SW \\
\hline & & \multirow{2}{*}{$\begin{array}{l}\text { Kerikil banyak } \\
\text { kandung an butian } \\
\text { halus }\end{array}$} & SM & Pasir ber hnau, campuran pasir-lanau & & 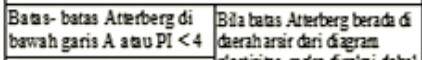 \\
\hline & & & $\mathrm{SC}$ & Pasir ber lempung, campuran pasir - lempung & & \begin{tabular}{|l|l} 
Batas-batas Attriberg di \\
bawah garis $\mathrm{A}$ anu $\mathrm{PI}>7$
\end{tabular} \\
\hline \multirow{6}{*}{ 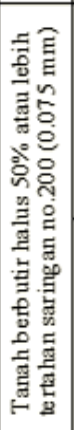 } & \multirow{3}{*}{\multicolumn{2}{|c|}{$\begin{array}{l}\text { Lanau dan lempung } \\
\text { batas cair } 50 \% \text { atau } \\
\text { kurang }\end{array}$}} & ML & 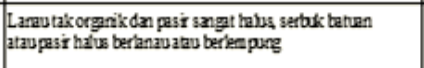 & \multirow{6}{*}{ 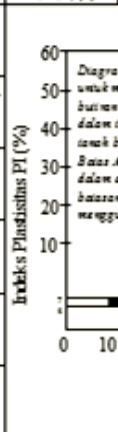 } & \\
\hline & & & $\mathrm{CL}$ & 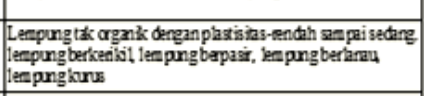 & & 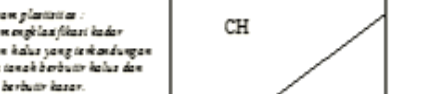 \\
\hline & & & $\mathrm{OL}$ & $\begin{array}{l}\text { Lanav organk dan lempung berlanau or ganilk dengan } \\
\text { phastisitas rendah }\end{array}$ & & $\begin{array}{l}\text { Anoth } \\
\text { isave } \\
\text { ankias }\end{array}$ \\
\hline & \multirow{3}{*}{\multicolumn{2}{|c|}{$\begin{array}{l}\text { Lanau dan lempung } \\
\text { batas cair }>50 \%\end{array}$}} & $\mathrm{MH}$ & $\begin{array}{l}\text { Lanav tak organk atav pasir halus diatomae, lanau } \\
\text { ehatis. }\end{array}$ & & $\mathrm{atan} O \mathrm{H}$ \\
\hline & & & $\mathrm{CH}$ & $\begin{array}{l}\text { Lanau tak organk dengan plastisias tinggi, lempung } \\
\text { gemuk }\end{array}$ & & \\
\hline & & & $\mathrm{OH}$ & $\begin{array}{l}\text { Lempung organik dengan plastistas sedang sampai } \\
\text { tinggi }\end{array}$ & & $\begin{array}{l}\text { Batas Car LL wa } \\
\text { Garis } A: P=0.73(L L-20)\end{array}$ \\
\hline \multicolumn{3}{|c|}{ Tanah dengan kadar organik tinggi } & $P_{t}$ & $\begin{array}{l}\text { Gambut dan tanah lain dengan landungan } \\
\text { organik tinggi }\end{array}$ & & $\begin{array}{l}\text { Manual untuk identifikasi secara visual dapat } \\
\text { dilihat di ASTM Designation D-2488 }\end{array}$ \\
\hline
\end{tabular}

Sumber: Hary Christady Hardiatmo (2006) 
Coulumb beranggapan bahwa selubung keruntuhan geser itu adalah merupakan garis lurus atau fungsi linear yang dituliskan dari persamaan:

$$
\tau=c+\sigma \tan \varnothing
$$

dimana :

$$
\begin{aligned}
\tau= & \text { kuat geser tanah }\left(\mathrm{kN} / \mathrm{m}^{2}\right) \\
\mathrm{c}= & \text { kohesi tanah }\left(\mathrm{kN} / \mathrm{m}^{2}\right) \\
\phi= & \text { sudut gesek dalam tanah atau } \\
& \text { sudut gesek intern }\left(^{0}\right) \\
\sigma= & \text { tegangan normal pada bidang } \\
& \text { runtuh }\left(\mathrm{kN} / \mathrm{m}^{2}\right)
\end{aligned}
$$

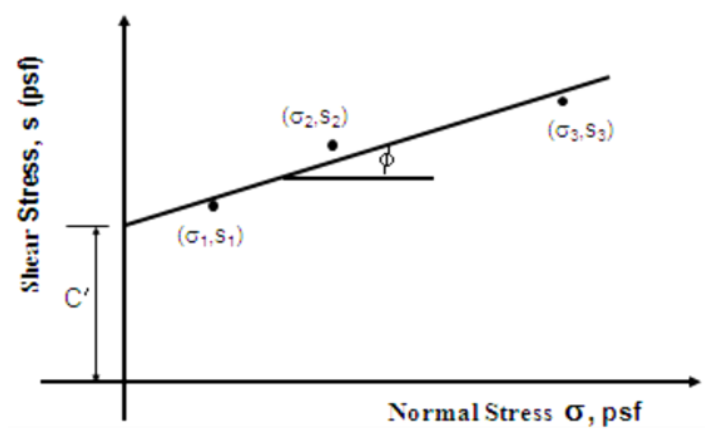

Gambar 1. Grafik hubungan tegangan normal Sumber : Bowles (1989) terhadap tegangan geser

Beberapa faktor yang mempengaruhi kuat geser tanah

Bowles (1986) mengemukakan, bahwa kuat geser bukanlah merupakan hal yang unik, tetapi tergantung pada beberapa hal antara lain: jenis tanah, kadar air, kepadatan, metode percobaan, dan lainlainnya. Kadar air tanah mempunyai efek penting terutama pada tanah jenis lempung. Pengaruh kadar air tanah terhadap kuat gesernya, bahwa makin besar kadar air tanah kuat geser akan terus menurun.

\section{Bahan Stabilisasi Semen}

Semen PC adalah bahan hidrolis yang dihasilkan dengan cara mencampurkan batu kapur yang mengandung kapur $(\mathrm{CaO})$ dan lempung yang mengandung silika $\left(\mathrm{S}_{\mathrm{i}} \mathrm{O}_{2}\right)$, oksida alumina $\left(\mathrm{AL}_{2} \mathrm{O}_{3}\right)$ dan oksida besi $\left(\mathrm{Fe}_{2} \mathrm{O}_{3}\right)$ dalam oven dengan suhu kira-kira $145^{\circ} \mathrm{C}$ sampai menjadi klinker. Klinker ini dipindahkan, digiling sampai halus disertai penambahan 3-5\% gips untuk mengendalikan waktu pengikat semen agar tidak berlangsung terlalu cepat .

Selain memenuhi persyaratan kimia dan fisik, semen juga mempuyai sifat-sifat lain seperti hidrasi semen, kekuatan pasta semen dan faktor air semen Hal yang penting mendapat perhatian adalah pengikatan dan pengerasanya. Pengikatan adalah peralihan dari keadaan keras, sedangkan pengerasan ialah penambahan kekuatan setelah pengikatan itu selesai. Pada proses pengikatan ada 2 tahap yaitu waktu awal pengikatan dan akhir pengikatan. Waktu awal pengikatan adalah waktu pada saat mulainya semen menjadi kaku terjadi dalam jam dan menit setelah semen itu diaduk menjadi air. Waktu akhir pengikatan adalah waktu sampai mencapai pastanya menjadi massa yang keras.

\section{Pemadatan Tanah}

Menurut Bowles (1993), pemadatan merupakan usaha untuk mempertinggi kerapatan tanah dengan memakai energi mekanis untuk menghasilkan pemampatan partikel. Energi mekanis yang digunakan 
dalam proses pemadatan dapat merupakan usaha dari penumbukan (impact), penekanan, penggetaran, dan penggilasan. Menurut Craig (1987), pemadatan (compaction) adalah proses naiknya kerapatan tanah dengan memperkecil jarak antar partikel sehingga terjadi penyempitan volume udara.

Menurut Sosrodarsono dan Nakazawa (2005), bahwa hubungan antara berat isi kering (dry density) dari tanah yang di padatkan dengan kadar air adalah berubahubah secara parabolis atau lengkungan. Harga maksimum dari berat isi kering disebut berat isi kering maksimum (maximum dry density) dan kadar air yang diperoleh dari pemadatan ini disebut kadar air optimum (optimum water content).

Das (1993) mengemukakan bahwa percobaan-percobaan pemadatan di laboratorium yang umum dilakukan untuk mendapatkan berat volume kering maksimum dan kadar air optimum adalah pengujian pemadatan dengan standar proctor. Prosedur pelaksanaan pengujian proctor standar telah dirinci dalam ASTM Test Designation T-99.

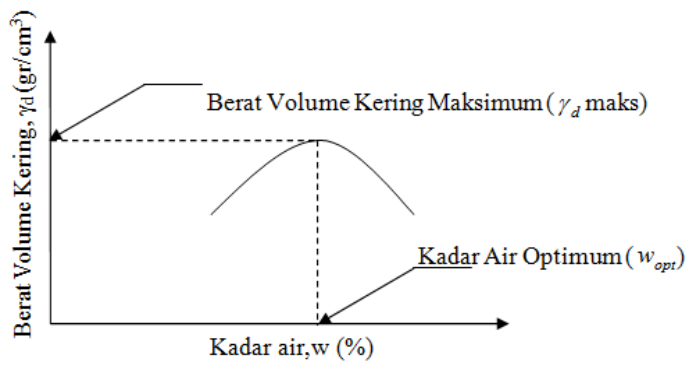

Gambar 2. Grafik hubungan kadar air dengan berat volume kering Sumber : Hary Christady Hardiatmo (2006)

\section{METODE PENELITIAN}

Pekerjaan awal yang dilakukan berupa pengambilan contoh tanah dan diangkut ke laboratorium untuk dilakukan pengukuran sifat fisis dan mekanis.

\section{Pengumpulan Data}

Data yang diperlukan dalam penelitian ini meliputi data primer dan data sekunder. Data primer adalah data yang diperlukan sebagai pendukung utama dalam analisis hasil penelitian. Data ini diperoleh dari hasil pemeriksaan atau pengujian langsung di laboratorium. Adapun data yang termasuk ke dalam data primer yaitu data sifat-sifat fisis seperti berat jenis, batas plastis, batas cair serta analisa butiran, dan data sifat mekanis yang berupa kepadatan optimum dan nilai pengembangan. Data sekunder merupakan data pendukung data primer yang diperlukan dalam penelitian yaitu berupa angka koreksi benda uji, angka kalibrasi alat pengujian, serta sketsa lokasi pengambilan tanah dan lain sebagainya. Data sekunder diperoleh dari instansi-instansi yang terkait dari studi literatur dan konsultasi.

\section{Peralatan yang digunakan}

Material yang digunakan pada penelitian ini adalah tanah dan semen pc. Baik itu untuk pengukuran sifat-sifat fisis maupun pengukuran mekanik. Penelitian ini terdiri dari tiga pengujian utama yaitu pengujian sifat-sifat fisis tanah (mulai dari $0 \%, 4 \%, 8 \%$, $12 \%$ dan 16\%), selanjutnya percobaan pemadatan tanah dan pengujian geser langsung. Pada pengujian sifat-sifat fisis 
tanah, peralatan yang digunakan terdiri dari flask, sungkup vacum, timbangan, satu set saringan, mangkuk casagrande, hidrometer, thermometer, mixer dan oven.

Pengujian mekanis memakai alat yang terdiri dari mold proctor (cetakan) yang berbentuk silinder yang terbuat dari besi, timbangan, gelas ukur, pisau perata tanah, dan extruderyang digunakan terdiri dari dongkrak dan kerangka besi.

\section{Pengambilan sampel tanah}

Tanah yang digunakan pada penelitian ini adalah tanah lempung (soil of clay) yang berasal dari kawasan Desa Lampoh Keude Kecamatan Kuta Baro Kabupaten Aceh Besar, tanah lempung yang digunakan merupakan sampel tanah terganggu (disturbed sample), dan diambil dengan menggunakan sekop. Tanah dimasukkan ke dalam karung dan dibawa ke Laboratorium Mekanika Tanah Fakultas Teknik Unsyiah, kemudian tanah tersebut dimasukkan kedalam oven dengan suhu $115^{\circ} \mathrm{C}$, selama 24 jam. Tanah tersebut selanjutnya ditumbuk dengan menggunakan palu. Hal ini dilakukan untuk mempermudah memecahkan gumpalan tanah sehingga tanah mudah untuk disaring.

\section{Pencampuran (Stabilisasi)}

Pencampuran tanah dengan semen, dengan cara mencampurkan tanah dan semen secara merata didalam suatu wadah, untuk mengetahui bebarapa banyak tanah dan semen yang akan dicampur, terlebih dahulu harus diketahui berat tanah untuk satu sampel, kadar air rata-rata, kadar air optimum (OMC = Optimum Moisture Content) dan berat volume kering maksimum $\left(\gamma_{\mathrm{d}} \max \right)$. Dari perhitungan tersebut akan diperoleh semen dan air yang akan diperlukan dalam pencampuran tanah.

Setelah tanah dan semen tersebut merata lalu ditambahkan dengan air yang telah dihitung banyaknya. Air tersebut diukur dengan cara memasukannya ke dalam gelas ukur. Lalu tanah yang telah selesai diaduk dimasukkan ke dalam kantong plastik. Hal ini untuk menjaga agar kadar air dalam tanah tidak berkurang.

Adapun dalam penelitian ini diuji 3 sampel untuk setiap persentase pencampuran bahan-bahan stabilisasi. Berikut ini ditampilkan dalam tabel variasi campuran bahan stabilisasi tanah asli.

\section{Tabel 3. Variasi benda uji}

\begin{tabular}{|c|c|c|}
\hline No. & Jenis Pengujian & Jumlah Sampel \\
\hline 1. & Tanah Asli & 3 buah \\
\hline \multirow{2}{*}{2.} & Tanah Asli + Semen & 3 buah \\
& $-4 \%$ Semen & 3 buah \\
& $-8 \%$ Semen & 3 buah \\
& $-12 \%$ Semen & 3 buah \\
& $-16 \%$ Semen & 3 buah \\
\hline & Jumlah Sampel & 18 buah \\
\hline
\end{tabular}

\section{Pembuatan Benda Uji Untuk}

\section{Pengujian Geser Langsung}

Pembuatan masing-masing benda uji melalui pemadatan dengan kadar air optimum diambil dari hasil pengujian proctor test, berat tanah tiap mold 2.100 gram, berat mold 4,961 $\mathrm{kg}$, luas mold $1.105 \mathrm{~cm}^{2}$, tinggi jatuh penumbuk 30,5 cm dengan 25 kali tumbukan 
dengan 3 lapisan dengan masa tunggu pemeraman 1 x 24 jam. Sampel tanah dari mold dikeluarkan dengan ekstruder. Setelah sampel dikeluarkan dan dilakukan koreksi terhadap tinggi sampel dengan cara memotong sampel dengan wire saw, tiap mold dicetak benda uji sebanyak 3 buah untuk pengujian geser langsung dengan menggunakan cutting ring (ring cetak), dengan tinggi sampel $2 \mathrm{~cm}$ dan berdiameter $6,3 \mathrm{~cm}$, luas sampel $31,157 \mathrm{~cm}^{2}$.

\section{Pengujian Geser Langsung}

Test ini dimaksudkan untuk menentukan nilai kohesi (c) dan sudut geser dalam (ø) secara cepat. Adapun peralatan yang digunakan dalam pengujian ini yaitu: loading machine, shear box, loads, sample tube, proving ring, dial indicator 2 buah, wire saw, dan peralatan tambahan yaitu: moisture content test set, wash bottle, stop watch, vernier caliper, spatula.

Adapun prosedur pengujian ini, siapkan benda uji sebanyak 3 buah, masukkan contoh tanah kedalam tabung pembuat yaitu (sample tube), kemudian keluarkan dengan alat pengeluarnya (extruder). Ratakan tanah yang menonjol dikedua ujung benda uji dengan pisau pemotong (wire saw), timbang sampel dengan ketelitian 0,1 gram, stel bak geser (shear box) dimana plat geser bawah diletakkan pada permukaan dasar bak perendam kemudian kencangkan bak pengunci. Setalah itu pasang plat geser bawah diletakkan pada permukaan dasar bak perendam kemudian kencangkan baut pengunci.

Setelah itu pasang plat geser atas, kemudian pasang pen sehingga plat geser bawah dan atas lubangnya akan simetris. Kemudian masukan plat alas, dan batu pori. Setelah itu letakkan sampel tanah kemudian himpit dengan batu pori dan penekan contoh. Pasang instalasi muatan dan palang kecilnya akan berhubungan dengan lengan keseimbangan, kemudian atur handle stelan seimbangnya. Pasang dial pergeseran dan proving ring. Atur posisi jarum pergeseran pada angka nol dan atur pula dial proving ring pada angka nol. Isi bak perendam dengan air sesuai kebutuhan. Pasang beban pertama 0,509 kg. Buka pen pengunci lalu putar pen perenggang, putar engkol sehingga tanah mulai menerima beban geser.

Baca dial pergeseran setiap 15 detik sampai tercapai beban maksimum atau deformasi $10 \%$ diameter benda uji. Masukan sampel kedua sesuai prosedur, gunakan beban $1,536 \mathrm{~kg}$. Untuk sampel ketiga lakukan seperti prosedur, gunakan beban $3,59 \mathrm{~kg}$. Perawatan dilakukan dengan cara mengeringkan bak perendam setelah percobaan selesai. Bersihkan cincin geser terutama bidang gesernya agar tidak terjadi hambatan bila diberikan beban horizontal. Lumasi as pendorong yang menempel pada proving ring agar dapat bergerak bebas tanpa hambatan. Buka box gigi penggeraknya. Buka keempat baut tersebut lalu periksa isi box tersebut, kencangkan baut (borg) penahan gigi dan tambahkan oli secukupnya, 
putar engkol maju mundur sampai lancar.

\section{HASIL PEMBAHASAN}

Klasifikasi menurut AASHTO

(American Association of State Highway and Transportation Officials) dilakukan berdasarkan hasil analisis saringan dan pengujian sifat-sifat fisis tanah. Data dari hasil analisis saringan pada Tabel 4 menunjukkan bahwa tanah yang lolos saringan nomor 200 (Ø $0,074 \mathrm{~mm}$ ) adalah 54,03\% lebih dari $36 \%$, sehingga tanah tersebut termasuk tanah lempung dengan simbol kelompok A-4, A-5, A-6, dan A-7. Berdasarkan batas cair (LL) sebesar $54,25 \%$ yang lebih besar dari $40 \%$, dan indek plastis (PI) sebesar 25,68\% yang lebih besar dari $11 \%$, maka tanah tersebut dimasukkan dalam kelompok A-7. Kelompok A-7 dibagi lagi atas A-7-5 dan A-7-6. Apabila indeks plastis lebih kecil sama dengan batas cair kurang 30 (PI $\leq$ LL-30), maka tanah tersebut dapat digolongkan ke dalam tanah dengan golongan A-7-5 dan apabila indeks plastis lebih besar dari batas cair kurang 30 (PI > LL-30), maka tanah tersebut dapat digolongkan ke dalam tanah dengan golongan A-7-6. Berdasarkan indeks plastis sebesar 25,68 tanah tersebut digolongkan ke dalam kelompok A-7-6.

Tabel 4. Hasil pengujian sifat-sifat fisis tanpa campuran

\begin{tabular}{|c|l|c|}
\hline No. & \multicolumn{1}{|c|}{ Parameter Pengujian } & Tanah Lempung \\
\hline 1. & Berat jenis & 2,470 \\
2. & Batas cair (\%)| & 54,25 \\
3. & Batas plastis (\%) & 28,57 \\
4. & Indeks plastis (\%) & 25,68 \\
5. & Persen lolos saringan no. 200 & 54,03 \\
\hline
\end{tabular}

Kualitas tanah tersebut dapat ditentukan berdasarkan indeks kelompoknya. Indeks kelompok ditentukan dari nilai batas cair, indeks plastis dan persentase butiran yang lolos saringan 200, dengan menggunakan Persamaan 2.1 yaitu $G I=(0,2 \times 19)+(0.05 \mathrm{x}$ $19 \times 14)+(0,01 \times 39 \times 16)=23$ maka didapat indeks kelompoknya sebesar 16 . Nilai yang didapat ini menunjukkan bahwa tanah Desa Lampoh Keude termasuk tanah lempung yang tergolong kedalam kelompok A-7-6 (16).

Penentuan jenis tanah menurut sistem USCS didasarkan pada analisis saringan, batas cair dan batas plastis. Berdasarkan analisa saringan menunjukkan bahwa tanah yang lolos saringan 200 adalah $54,03 \%$ yaitu lebih besar dari $50 \%$, sehingga tanah tersebut dimasukkan kedalam fraksi tanah yang berbutir halus. Berdasarkan nilai batas cair sebesar $54,25 \%$ yaitu lebih besar dari $50 \%$, tanah tersebut dimasukkan ke dalam kelompok $\mathrm{CH}$.

Tabel 5. Kadar air pemadatan

\begin{tabular}{|c|c|c|c|c|c|c|}
\hline \multirow{2}{*}{ No. } & \multirow{2}{*}{$\begin{array}{c}\text { Parameter } \\
\text { Pengujian } \\
\text { Pemadatan }\end{array}$} & $\begin{array}{c}\text { Tanah } \\
\text { Tanpa } \\
\text { Campuran }\end{array}$ & \multicolumn{4}{|c|}{ Variasi Persentase Campuran } \\
\cline { 4 - 7 } & $\mathbf{4} \%$ & $\mathbf{8} \%$ & $\mathbf{1 2} \%$ & $\mathbf{1 6 \%}$ \\
\hline 1 & $\begin{array}{l}\text { Berat volume } \\
\text { kering maksimum } \\
\left(\gamma_{\text {dmaks }}\right)\left(\mathrm{gr} / \mathrm{cm}^{3}\right)\end{array}$ & 1,438 & 1,438 & 1,438 & 1,438 & 1,438 \\
\hline \multirow{2}{*}{2} & $\begin{array}{l}\text { Kadar air optimum } \\
\text { (Optimum Moisture } \\
\text { Content })(\%)\end{array}$ & 23,15 & 23,15 & 23,15 & 23,15 & 23,15 \\
\hline
\end{tabular}

Tabel 6a. Data parameter kohesi sudut geser pada campuran semen $0 \%$

\begin{tabular}{|c|c|c|c|}
\hline $\begin{array}{c}\text { Tegangan } \\
\text { normal }(\sigma) \\
\left(\mathrm{kg} \mathrm{cm}^{2}\right)\end{array}$ & $\begin{array}{c}\text { Tegangan } \\
\text { geser }(\tau) \\
(\mathrm{kg} \mathrm{cm})\end{array}$ & $\begin{array}{c}\text { Kohesi }(\mathrm{c}) \\
(\mathrm{kg} \mathrm{cm})\end{array}$ & Sudut geser $(\phi)$ \\
\hline 0.305 & 0.971 & & $31.45^{\circ}$ \\
0.634 & 1.202 & 0.797 & \\
1.293 & 1.582 & & \\
\hline
\end{tabular}


Tabel 6b. Data parameter kohesi sudut geser pada campuran semen $4 \%$

\begin{tabular}{|c|c|c|c|}
\hline $\begin{array}{c}\text { Tegangan } \\
\text { normal }(\sigma) \\
\left(\mathrm{kg} / \mathrm{cm}^{2}\right)\end{array}$ & $\begin{array}{c}\text { Tegangan } \\
\text { geser }(\tau) \\
\left(\mathrm{kg} / \mathrm{cm}^{2}\right)\end{array}$ & $\begin{array}{c}\text { Kohesi }(\mathrm{c}) \\
\left(\mathrm{kg} / \mathrm{cm}^{2}\right)\end{array}$ & Sudut geser $(\phi)$ \\
\hline 0,305 & 1,608 & & \\
0,634 & 1,704 & $1,326 \mathrm{gr} / \mathrm{cm}^{2}$ & $36,22^{\circ}$ \\
1,293 & 2,303 & & \\
\hline
\end{tabular}

Tabel 6c. Data parameter kohesi sudut geser pada campuran semen $8 \%$

\begin{tabular}{|c|c|c|c|}
\hline $\begin{array}{c}\text { Tegangan } \\
\text { normal }(\sigma) \\
\left(\mathrm{kg} / \mathrm{cm}^{2}\right)\end{array}$ & $\begin{array}{c}\text { Tegangan } \\
\text { geser }(\tau) \\
\left(\mathrm{kg} / \mathrm{cm}^{2}\right)\end{array}$ & $\begin{array}{c}\text { Kohesi }(\mathrm{c}) \\
\left(\mathrm{kg} / \mathrm{cm}^{2}\right)\end{array}$ & $\begin{array}{c}\text { Sudut } \\
\text { geser }(\phi)\end{array}$ \\
\hline 0,305 & 1,715 & & \\
0,579 & 2,119 & $1,559 \mathrm{~kg} / \mathrm{cm}^{2}$ & $37,80^{\circ}$ \\
1,293 & 2,532 & & \\
\hline
\end{tabular}

Tabel 6d. Data parameter kohesi sudut geser pada campuran semen $12 \%$

\begin{tabular}{|c|c|c|c|}
\hline $\begin{array}{c}\text { Tegangan } \\
\text { normal }(\sigma) \\
\left(\mathrm{kg} / \mathrm{cm}^{2}\right)\end{array}$ & $\begin{array}{c}\text { Tegangan } \\
\text { geser }(\tau) \\
\left(\mathrm{kg} / \mathrm{cm}^{2}\right)\end{array}$ & $\begin{array}{c}\text { Kohesi }(\mathrm{c}) \\
\left(\mathrm{kg} / \mathrm{cm}^{2}\right)\end{array}$ & $\begin{array}{c}\text { Sudut } \\
\text { geser }(\phi)\end{array}$ \\
\hline 0,305 & 2,184 & & \\
0,579 & 2,411 & $1,950 \mathrm{~kg} / \mathrm{cm}^{2}$ & $38,11^{\circ}$ \\
1,293 & 2,963 & & \\
\hline
\end{tabular}

Tabel 6e. Data parameter kohesi sudut geser pada campuran semen $16 \%$

\begin{tabular}{|c|c|c|c|}
\hline $\begin{array}{c}\text { Tegangan } \\
\text { normal }(\sigma) \\
\left(\mathrm{kg} / \mathrm{cm}^{2}\right)\end{array}$ & $\begin{array}{c}\text { Tegangan } \\
\text { geser }(\tau) \\
\left(\mathrm{kg} / \mathrm{cm}^{2}\right)\end{array}$ & $\begin{array}{c}\text { Kohesi }(\mathrm{c}) \\
\left(\mathrm{kg} / \mathrm{cm}^{2}\right)\end{array}$ & $\begin{array}{c}\text { Sudut } \\
\text { geser }(\phi)\end{array}$ \\
\hline 0,305 & 2,239 & & \\
0,579 & 2,679 & $2,084 \mathrm{~kg} / \mathrm{cm}^{2}$ & $39,01^{\circ}$ \\
1,293 & 3,096 & & \\
\hline
\end{tabular}

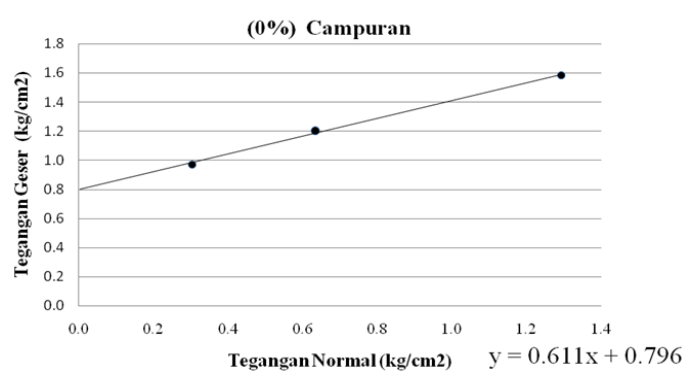

Gambar 3a. Grafik $\sigma-\tau$ pada $0 \%$ campuran semen

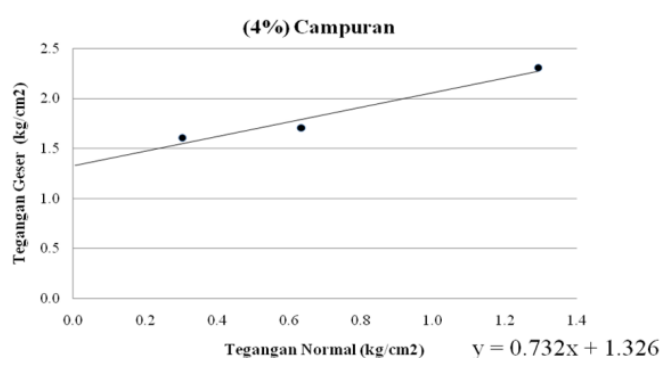

Gambar 3b. Grafik $\sigma-\tau$ pada $4 \%$ campuran semen

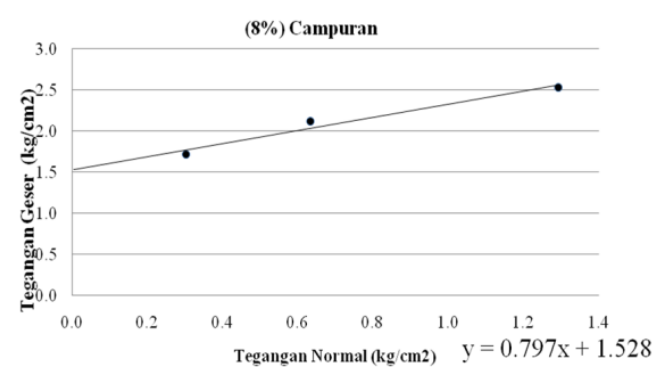

Gambar 3c. Grafik $\sigma-\tau$ pada $8 \%$ campuran semen

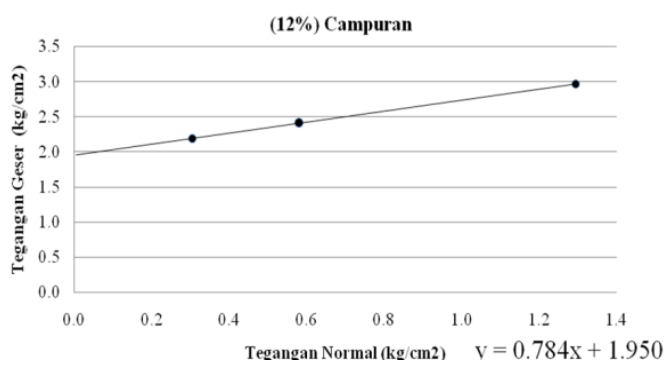

Gambar 3d. Grafik $\sigma-\tau$ pada $12 \%$ campuran semen

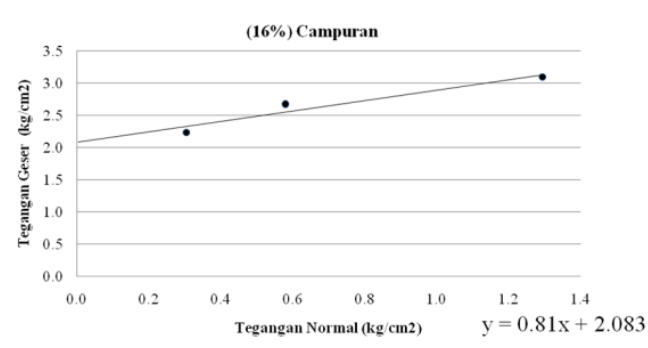

Gambar 3e. Grafik $\sigma$ - $\tau$ pada $16 \%$ campuran semen

Penggunaan semen pada material tanah lempung asal Desa Lampoh Keude Kecamatan Kuta Baro Kabupaten Aceh Besar berpengaruh terhadap peningkatan parameter nilai ø dan c. Benda uji tanah yang dicampur dengan bahan stabilisasi berupa semen pada 
material tanah lempung memiliki nilai ø dan c lebih tinggi dibandingkan dengan benda uji yang tidak dicampur dengan bahan stabilisasi. Dengan meningkatnya nilai $\varnothing$ dan c berarti meningkat pula kemampuan daya dukung tanah tersebut. Dengan demikian penggunaan semen untuk tanah yang mengandung lempung sangat efektif untuk meningkatkan kemampuan daya dukung tanah. Berdasarkan hasil yang diperoleh, semakin tinggi persentase penambahan semen semakin tinggi pula nilai ø dan c. Hal ini dapat dilihat pada semen campuran $4 \%, 8 \%, 12 \%$ dan $16 \%$ menunjukan nilai $\varnothing$ dan c yang terus meningkat. Semen berfungsi sebagai material yang merubah sifat-sifat fisis dan mekanis tanah secara proses kimia.

\section{KESIMPULAN DAN SARAN}

\section{Kesimpulan}

1. Tanah lempung Desa Lampoh Keude termasuk ke dalam lempung anorganik dengan plastisitas tinggi yang disimbolkan dengan $\mathrm{CH}$ menurut sistem USCS dan termasuk golongan A-7-6 menurut sistem klasifikasi AASHTO.

2. Penambahan campuran semen dapat meningkatkan nilai $\varnothing$ dan c tanah lempung.

3. Semen dapat digunakan sebagai material stabilisasi tanah lempung dan mampu menambah daya dukung tanah.

4. Kuat geser tanah lempung meningkat sejalan dengan penambahan kadar semen.

\section{Saran}

Penelitian tanah lempung Desa Lampoh Keude agar dilanjutkan dengan material stabilisasi lain seperti bahan yang dihasilkan dari limbah industri, dengan demikian dapat membantu mengurangi sampah industri yang terbuang percuma.

\section{DAFTAR PUSTAKA}

Bowles, J. E., \& Johan K. Hainim 1993. Sifat-sifat Fisis dan Geoteknis Tanah (Mekanika Tanah). Edisi ke dua. Jakarta: Erlangga.

Craig. R.F., 1987. Mekanika Tanah. Edisi ke empat. Jakarta: Erlangga.

Das, B.M., 1993. Mekanika Tanah (Prinsip-prinsip Rekayasa Geoteknis). Jakarta: Erlangga.

Dunn, I. S, Anderson, L. R Kiefer, 1992. Dasar-Dasar Analisis Geoteknik, IKIP Semabu: Tempurung Kelapa Press.

Hardiyatmo, C. H, 2006. Mekanika Tanah

I. Yogyakarta: Fakultas Teknik Universitas Gajah Mada.

Ismail,M.A., 1995. Buku Petunjuk Pratikum Mekanika Tanah dan Cara Menulis Laporan. Banda Aceh: Fakultas Teknik Universitas Syiah Kuala.

Purnomo, E.S.J \& G.D. Soedarmo, 1997. Mekanika Tanah 2. Malang: Kanisius.

Sosrodarsono, S, \& Nakazawa, K, 2005. Mekenika Tanah dan Teknik Pondasi. Jakarta: Pradn 